\title{
Postpartum urinary retention: what are the sequelae? A long-term study and review of the literature
}

\author{
Stefan Mohr ${ }^{1} \mathbb{D} \cdot$ Luigi Raio $^{1} \cdot$ Ursula Gobrecht-Keller $^{2} \cdot$ Sara Imboden $^{1} \cdot$ Michael D. Mueller $^{1} \cdot$ Annette Kuhn $^{1}$
}

Received: 30 August 2021 / Accepted: 18 December 2021 / Published online: 7 February 2022

(c) The Author(s) 2022

\begin{abstract}
Introduction and hypothesis Postpartum urinary retention (PUR) may cause long-term urogenital tract morbidity. The incidence ranges from 0.18 to $14.6 \%$, but the importance of prompt diagnosis and appropriate management is often underappreciated. The paucity of data on long-term outcome after PUR contributes to these drawbacks. The aim of this study was to assess long-term persistence of elevated PVR (post-void residual urine) volume after PUR. Pathophysiology, risk factors and management of PUR are reviewed.

Methods In our tertiary referral urogynecology unit in the University Women's Hospital of Bern, Switzerland, all patients who were referred for PUR were asked to participate in this study. PVR was measured sonographically every 2 days until day 15 , then after $6,12,24$ and 36 months and, if increased, the patients were instructed to perform clean intermittent selfcatheterization. If retention persisted longer than the lactation period, multichannel urodynamics was performed.

Results Sixty-two patients were included. The median PVR normalized at day 7. Long-term voiding disorders were found in $8.2 \%, 6.7 \%$, and $4.9 \%$ after 1, 2, and 3 years respectively. Multichannel urodynamics confirmed in all patients with persisting retention an acontractile detrusor and de novo stress urinary incontinence in 4 cases. Quantile regression did not reveal any factor contributing to earlier recovery. Eighty-nine percent of the patients with PUR had operative vaginal deliveries, emphasizing the importance of this risk factor for PUR.

Conclusions In most cases PUR resolves early, but voiding difficulties persist more often than previously thought, and for these patients the consequences are devastating. Obstetric awareness, early active management, and developing management strategies in the postpartum period might preclude lower urinary tract morbidity.
\end{abstract}

Keywords Postpartum urinary retention $\cdot$ Residual urine $\cdot$ Post-void residual volume $\cdot$ Overt urinary retention $\cdot$ Covert urinary retention $\cdot$ Voiding problems

\section{Introduction}

Postpartum urinary retention (PUR) is a serious and frequent complication after childbirth [1-3]. Overt PUR has been defined as the inability to void within $6 \mathrm{~h}$ of delivery or after removal of the catheter, whereas covert PUR means an increased post-void residual urine volume (PVR) of more than $150 \mathrm{ml}$ after spontaneous micturition $[1,4]$.

Stefan Mohr

stefan.mohr@insel.ch

1 Department of Obstetrics and Gynecology, Inselspital, Bern University Hospital, University of Bern, Friedbühlstrasse 19, 3010 Bern, Switzerland

2 Department of Obstetrics and Gynecology, Basel University Hospital, Basel, Switzerland
The incidence of PUR ranges from 0.18 to $47 \%$ [1-16] depending on the varying definitions and the time interval of follow-up used.

The pathophysiology of PUR is poorly understood. Several theories have been suggested, including physiological, neurological, and mechanical processes during pregnancy and delivery $[1,2,6]$. Levator ani muscle avulsion seems to be associated with persistent postpartum voiding dysfunction [17], but the etiology of PUR is thought to be multifactorial. Trauma to the pelvic floor muscles, the detrusor muscle itself, and overdistention of nerve fibers might impair bladder sensitivity, cause periurethral obstructing edema, and hormonal changes may influence bladder function as well $[1,2]$. PUR can lead to denervation, detrusor atony, and bladder dysfunction if it is not recognized in time [2, $13,16,18]$. Although long-term consequences of PUR are 
rarely reported [19] and small studies showed negligible if any clinical impact on long-term urogynecological disorders [19], only a few data are available on the potential longterm micturition problems of increased PVR after vaginal delivery [20]. Persistent urinary retention can be a serious condition for the patient and requires management in order to prevent urogenital tract morbidity such as micturition problems due to detrusor failure, kidney failure, anuria, and hydronephrosis [1, 2], even in later life [16]. Complications such as urothelial lesions [21] and urinary bladder rupture have been described $[22,23]$. Prompt diagnosis and appropriate management are the key to restoring normal bladder function $[1,2]$, but recognition is hampered by a low level of awareness amongst obstetric units and a scarcity of published literature [24].

Risk factors for PUR include: a prolonged second stage of labor [2, 4-6, 8, 18, 25-29] (duration of labor [first and second stage $]>700$ min predicts PUR $[8,30]$ ), vacuum-assisted $[2,25]$, and instrumental delivery $[5,6,8-11,14,23,26,27$, $29,31,32]$, (high grade) perineal lacerations $[3,6,10,13$, 18, 25-27, 29, 31, 33], and episiotomy [5, 9, 11, 16, 18, 23, $33]$, degree of perineal pain [5], fetal birth weight [6,16, 18, 32], use of systemic narcotics [16, 29], nulliparity [3, 5, 6, 9, $11,13,23,25-27]$, cesarean section (possibly after failure to progress in labor) $[12,13,28,32,33]$, epidural analgesia (possibly by modifying other obstetrical parameters such as duration of labor) [5, 7, 9, 15, 16, 23, 25-27, 29, 32], intermittent catheterization during labor [3], an increasing number of catheterizations [34], and an absence of spontaneous voiding before leaving the delivery room [31]. One study identified urination just before delivery as a preventive factor for PUR [11].

Commonly, PUR is thought to be transient [1, 4], possibly because PVR is not routinely measured and therefore PUR is underdiagnosed, but data to sustain the transient nature of PUR are scarce $[1,20]$.

In particular, there is a paucity of data on long-term outcome after postpartum urinary retention and time period to normalization of post-void residual urine volume. The aim of this study was to assess long-term persistence of elevated post-void residual urine volume after PUR. We hypothesize that postpartum urinary retention does not necessarily resolve spontaneously in all women.

\section{Materials and methods}

We performed a prospective cohort study in our tertiary referral urogynecology unit in the University Women's Hospital of Bern, Switzerland. In our Department 2,300 babies are delivered annually and we have 65 gynecological beds. The rate of vaginal operative delivery is $13 \%$ in our hospital. Patients who were referred to our unit for immediate PUR from our own maternity ward, as well as from outside hospitals, were asked to participate in this study. All patients were referred on the day of or after delivery because the PVR was greater than $500 \mathrm{cc}$ or the patient was symptomatic or not able to void at all. Ethical consent from the local ethics committee was obtained (Kantonale Ethikkommission Bern, 16-04-2008) and patients were asked to sign consent forms. The primary outcome was the time to normalization of post-void residual urine, the secondary outcomes were influencing factors for persistent increased volumes.

At first visit, demographic data, obstetric data such as mode of delivery, birth weight, type of anesthetic, and obstetric complications were noted.

Post-void residual urine was measured using ultrasound (Aloka Systems, Japan) applying the curved array 3.5-MHz probe immediately after micturition with the formula width $\times$ length $\times$ depth $\times 0.6$ [35]. Residual urine was defined as significant if more than $150 \mathrm{ml}$ were measured. Immediately after the diagnosis of retention was made a permanent catheter was placed for $24 \mathrm{~h}$, then removed, and patients were instructed to perform clean intermittent self-catheterization afterwards.

Self-catheterization was instructed by specialized incontinence nurses in an outpatient setting. Catheter choice and the patient's position during catheterization were performed according to patients' preference and manual abilities, and catheter intervals were prescribed according to the amount of residual urine, aiming at not surpassing the bladder capacity of more than $500 \mathrm{ml}$. Patients were catheterized depending on residual urine volume, i.e., once a day over $100 \mathrm{ml}$, twice a day over $200 \mathrm{ml}$, and so forth. At follow-up, difficulties using the self-catheterization were noted. Patients were asked to fill in a voiding-residual diary. In case of an inability to self-catheterize, a transurethral Foley catheter was offered.

Initially, residual was measured every 2 days until day 15, then after 6 months and 12 months. After this, patients were asked to attend our clinic for follow-up on a yearly basis.

In cases of retention that lasted longer than the lactation period, multichannel urodynamics was performed according to ICS recommendations [36]. Briefly, multichannel urodynamics were performed in the sitting $45^{\circ}$ upright position. Filling was continued until the patient experienced a strong desire to void. At bladder capacity pressure flow studies were performed. Side effects of self-catheterization, de novo symptoms, and urinary tract infections were noted. For statistical analysis, GraphPad Prism, version 6.0 for Windows, was used. Additionally, both Cox regression and quantile regression were used to explore factors influencing time to normal urinary retention $(\leq 150 \mathrm{ml})$. Quantile regression estimates how much a predictor influences the median of the variable of interest, in this case, time to normal urinary 
retention. These analyses were performed with Stata 16.1, StataCorp 2019.

\section{Results}

All 62 patients who were asked to participate were included in this study. Median age was 29 years (range 17 to 45 ). Median body mass index (BMI) was $27 \mathrm{~kg} / \mathrm{m}^{2}$ (range 19 to 34 ). Parity was 1 in 37 women, 2 in 12 patients, 3 in 5 women, parity 5 in 4 women and 8 in 3 women. For 1 patient demographic data were not retrievable.

Delivery mode was instrumental in $88 \%$ : forceps extraction in 8 , vacuum-assisted delivery in 43 , and spontaneous delivery in 6 patients, and 1 had a cesarean section. In 4 patients the delivery mode was not retrievable. Sixty-one percent had an epidural anesthesia and $10 \%$ had a pudendal block.

Gestational age at delivery was $39+2$ weeks (range $33+0$ to $41+2$ ). Median blood loss during delivery was $500 \mathrm{ml}$ (range 200-1,500 ml). Mean duration of the first stage of labor was $432 \mathrm{~min}$ (range 189-670) and of the second stage it was $190 \mathrm{~min}$ (range 20-305) respectively. Birthweights showed a median of 3,900 g $(2,900-4,680)$. Head circumference was a median of $36 \mathrm{~cm}$ (range 31-39). All women had singleton deliveries.

The initial PVR was $\geq 2,000 \mathrm{ml}$ in 8 patients of whom 5, 4, and 3 had increased PVR after 12, 24, and 36 months respectively. The median residual volume postpartum normalized (i.e., went below $150 \mathrm{ml}$ ) at day 7 (Fig. 1, Table 1). Long-term voiding disorders (i.e., PVR $>150 \mathrm{ml}$ ) were found in 5 (8.2\%), 4 (6.7\%), and 3 (4.9\%) of patients after 1 , 2 , and 3 years respectively. Multichannel urodynamics confirmed in all patients with persisting retention an acontractile detrusor and de novo stress urinary incontinence in 4 cases. Lost-to-follow-up measurements were one woman after 12, two women after 24, and one woman after 36 months respectively, and these women were excluded from the respective analyses at these time points.

Quantile regression results for age, parity, BMI, spontaneous delivery, length of first and second stages of labor, birth weight, head circumference, and epidural were of no
Residual urine volume post partum $(n=62)$

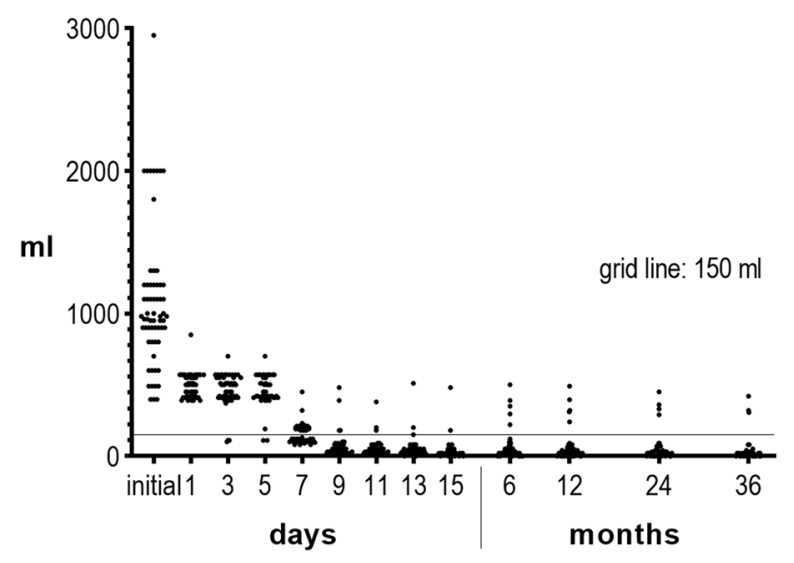

Fig. 1 Development of residual urine volume postpartum, i.e., measured every 2 days until day 15 , then after $6,12,24$ and 36 months

value owing to little variation in the data, partly due to the sampling method of sampling every 2 nd day. However, the only factor found to be of statistical significance was spontaneous birth (median $-2.00,95 \% \mathrm{CI}-2.22$ to -1.78 , $p<0.001)$. Spontaneous delivery seems to reduce the time to normal PVR by a median of 2 days (Tables 3 ).

\section{Discussion}

Our study shows that although being transient, in most cases persistent voiding disorders after postpartum urinary retention are not negligible, and if increased PVR does not resolve by day 7 postpartum it is likely to persist. Our findings show that $8.2 \%, 6.7 \%$, and $4.9 \%$ of the women have long-term voiding difficulties after 1,2 , and 3 years respectively, requiring intermittent clean self-catheterization after postpartum urinary retention (Fig. 1, Table 1). In the majority of cases normal voiding was re-established after 7 days, and patients with long-term voiding disorder had noticeably high initial residual volumes of $>2,000 \mathrm{ml}$ that reportedly persisted over several hours and were managed poorly with in-and-out catheters instead of adequate continuous
Table 1 Median residual urine volume measures in milliliters

\begin{tabular}{|c|c|c|c|c|c|c|c|c|c|c|c|c|c|}
\hline & \multirow[t]{2}{*}{ Initial } & \multicolumn{8}{|l|}{ Day } & \multicolumn{4}{|c|}{ Month } \\
\hline & & 1 & 3 & 5 & 7 & 9 & 11 & 13 & 15 & 6 & 12 & 24 & 36 \\
\hline Minimum (ml) & 399 & 390 & 100 & 110 & 80 & 20 & 20 & 0 & 0 & 0 & 0 & 0 & 0 \\
\hline Median (ml) & 980 & 500 & 500 & 435 & 120 & 50 & 50 & 30 & 20 & 22.5 & 30 & 30 & 20 \\
\hline Maximum (ml) & 2,950 & 850 & 700 & 700 & 450 & 480 & 380 & 510 & 480 & 500 & 490 & 450 & 420 \\
\hline $\begin{array}{l}\text { Number of } \\
\text { patients with } \\
\text { PVR } \geq 150\end{array}$ & 62 & 62 & 59 & 58 & 37 & 5 & 3 & 2 & 2 & 5 & 5 & 4 & 3 \\
\hline
\end{tabular}

(Bold: median volumes decreasing below $150 \mathrm{ml}$ and $100 \mathrm{ml}$, respectively, on day 7) 
drainage. Yet, for high initial residual volumes being a risk factor we were not able to demonstrate statistical significance, possibly because of the lack of variance in our data and the rare event of persistent long-term voiding problems.

Post-void residual volume is not uniformly defined and there is no consensus on what constitutes a significant elevation or at which volume PVR contributes to urinary problems [37-39]. The current cut-off values for covert PUR are rather arbitrary until data on the clinical consequences of abnormal PVR are available [16]. The arbitrary cut-off of $150 \mathrm{ml}$ in nonpregnant women does not exclude voiding dysfunction [40]. The Agency Health Care Research and Quality guidelines define a PVR of less than $50 \mathrm{ml}$ as being indicative of adequate emptying and a PVR of more than $200 \mathrm{ml}$ as inadequate emptying [37], but the range between 50 and $200 \mathrm{ml}$ remains ambiguous. Stricter definitions use a PVR cut-off of $100 \mathrm{ml}$ or one third of total volume, in contrast to $150-200 \mathrm{ml}$ or one half of total volume [41]. In men, covert urinary retention definitions range from 300 to $1,000 \mathrm{ml}$, reflecting the lack of clear cut-offs [42]. A change of the current definition of covert PUR was proposed to be $\geq 500 \mathrm{ml}$ after the first postpartum void because above this cut-off some women do need more time to normalize emptying of the bladder [20].

Previous research has shown that only two thirds of women achieve normal voiding within 4-14 days and another fifth within 15-28 days postpartum [2]. In most cases PUR resolves early (before hospital discharge [9] or within 4 days $[4,20]$ ), but PUR also can persist for a median of 19 (range 3-85 [7] or 1-45 [1]) days. Higher PVR 3 days after delivery is associated with increased risk for late recovery [2], which argues for early diagnosis and timely intervention avoiding long-term consequences [2]. Although covert retention was formerly stated to be self-limiting and specific treatment considered unnecessary [4], rates of protracted, persistent, or chronic PUR of 0.11\% [9], 0.18\% [2], 0.18\% [10], and $0.2 \%$ [7] are nevertheless alarming.

In our patients, the rate of persistent PUR was remarkably higher at $8.2 \%$ after 12 months, $6.7 \%$ at 24 months, and $4.9 \%$ after 3 years (Fig. 1, Table 1). One explanation may be the high number of patients with very large initial residual volumes of more than $1,000 \mathrm{ml}(n=29)$. These results are in contrast to those of Mulder et al., who stated that persistent PUR is common and transient and does not result in more lower urinary tract symptoms 1 year after delivery [20]. Although the absolute number of patients suffering from protracted PVR in the long term is low, the consequences for these individuals are immense.

Data on the treatment of postpartum urinary retention are scarce. Cholinergic medication was already suggested in 1957, but is known to have insufficient efficacy and results in side effects today [43]. PUR is commonly treated with (repeated) catheterization and/or instruction in intermittent self-catheterization $[1,7,10]$. Clean intermittent self-catheterization is preferred to indwelling catheterization, well tolerated, and not inferior regarding development of micturition symptoms [44-46]. Administration of antibiotics during catheterization is not beneficial and is not recommended [47].

In contrast to postoperative management in gynecological surgery, routine measurement of the PVR is not established in obstetrics [1,23], and the lack of guidelines is one of the major problems in treating women with PUR $[1,48,49]$. Systematic sonographic monitoring of all postpartum patients at least until day $3[15,49]$ and for $24 \mathrm{~h}$ after epidural analgesia [7] has been recommended to avoid excessive urinary retention. The most precise technique for measuring PVR is bladder catheterization [50], but, owing to being less invasive, both portable bladder scanning devices and 2D/3D ultrasound are to be favored [15, 51, 52], particularly because ultrasonic assessment is accurate enough to be used for making clinical decisions [53-55] and to screen women for residual volume in particular [51]. However, conflicting results exist regarding the accuracy of specific devices [50, 52].

As routine PVR measurements are time consuming and costly, a risk-factor-based approach has been proposed to only include patients at risk in purposeful sonographic monitoring [18], although this approach is controversial [13]. Knowledge of the risk factors might help to develop preventive measures $[18,31]$, improve early identification of women at risk, and lead to enhanced postpartum surveillance $[3,25]$, but further studies are needed to assess the efficiency of early systematic bladder scanning in patients with risk factors for PUR [31].

In line with the risk factors outlined in our introduction, the high rate of vaginal operative deliveries of $88 \%$ in our patients leads to the assumption that forceps and vacuum extraction are associated with PUR. Time until diagnosis/ management and urinary volume at first catheterization after delivery have been pointed out as risk factors for persistent PUR in particular [33], which again argues for attentive monitoring of postpartum voiding to minimize long-term complications. The analysis of our patients did not find any correlation between normalization of PVR after day 7 and 9 respectively, regarding age, BMI, spontaneous delivery, duration of 1st and 2nd stages of labor, birthweight, head circumference, duration of pregnancy, and epidural use (Table 2). Of note, these factors were analyzed regarding their influence on the time period to normalization of PVR and not as risk factors for PVR in general. Regarding the risk for prolonged PUR, we did not find increased hazard ratios for the above-mentioned factors (Table 3), but quantile regression revealed that in women with spontaneous delivery, the time to PVR normalization was reduced by 2 days compared with instrumental delivery. However, owing to the 
Table 2 Demographic and peripartum factors (left column) grouped by normalization of post-void residual urine at 7 and 9 days. $p$ values were calculated using Fisher's exact test and Wilcoxon/MannWhitney tests respectively, to compare if there were differences in the grouped factors between patients with normalized PVR and those with persistent PVR (i.e., if there were differences in age distribution between patients with normalized and those with persistent PVR)

\begin{tabular}{|c|c|c|c|c|c|c|c|}
\hline & Total $(n=62)$ & $\begin{array}{l}\text { PVR }>150 \mathrm{ml} \text { by } \\
\text { day } 7(n=44)\end{array}$ & $\begin{array}{l}\mathrm{PVR} \leq 150 \mathrm{ml} \text { by } \\
\text { day } 7(n=18)\end{array}$ & $p$ value day 7 & $\begin{array}{l}\text { PVR }>150 \mathrm{ml} \text { by } \\
\text { day } 9(n=4)\end{array}$ & $\begin{array}{l}\mathrm{PVR} \leq 150 \mathrm{ml} \text { by } \\
\text { day } 9(n=58)\end{array}$ & $p$ value day 9 \\
\hline & $\begin{array}{l}\text { Median (lq, uq) } \\
\text { or } n(\%)\end{array}$ & $\begin{array}{l}\text { Median (lq, uq) } \\
\text { or } n(\%)\end{array}$ & $\begin{array}{l}\text { Median (lq, uq) } \\
\text { or } n(\%)\end{array}$ & & $\begin{array}{l}\text { Median (lq, uq) } \\
\text { or } n(\%)\end{array}$ & $\begin{array}{l}\text { Median (lq, uq) } \\
\text { or } n(\%)\end{array}$ & \\
\hline Age (years) & $29(23,35)$ & $29(23,35)$ & $34(23,37)$ & 0.63 & $37[27,41]$ & $29[23,35]$ & 0.23 \\
\hline BMI $\left(\mathrm{kg} / \mathrm{m}^{2}\right)$ & $27(21,29)$ & $27(21,29)$ & $28(27,29)$ & 0.33 & $29(29,34)$ & $27(21,29)$ & 0.030 \\
\hline $\begin{array}{l}\text { Spontaneous } \\
\text { delivery }\end{array}$ & & & & 0.14 & & & 0.12 \\
\hline No & $52(84 \%)$ & $39(89 \%)$ & $13(72 \%)$ & & $2(50 \%)$ & $50(86 \%)$ & \\
\hline Yes & $10(16 \%)$ & $5(11 \%)$ & $5(28 \%)$ & & $2(50 \%)$ & $8(14 \%)$ & \\
\hline $\begin{array}{l}\text { 1st stage of labor } \\
\text { (min) }\end{array}$ & $390(320,580)$ & $343(320,580)$ & $470(340,580)$ & 0.64 & $508(343,670)$ & $390(320,580)$ & 0.19 \\
\hline $\begin{array}{l}\text { 2nd stage of } \\
\text { labor (min) }\end{array}$ & $190(90,200)$ & $170(90,198)$ & $190(90,210)$ & 0.83 & $195(193,198)$ & $150(90,210)$ & 0.22 \\
\hline Birthweight (kg) & $3.9(3.5,4.1)$ & $3.9(3.4,4.1)$ & $3.7(3.5,4.0)$ & 0.67 & $3.9(3.8,4.2)$ & $3.8(3.3,4.1)$ & 0.33 \\
\hline $\begin{array}{l}\text { Head circumfer- } \\
\text { ence }(\mathrm{cm})\end{array}$ & $36(35,36)$ & $36(35,36)$ & $36(35,36)$ & 0.97 & $36(36,37)$ & $36(35,36)$ & 0.40 \\
\hline $\begin{array}{l}\text { Duration of preg- } \\
\text { nancy (days) }\end{array}$ & $275(263,280)$ & $267(258,280)$ & $278(263,280)$ & 0.45 & $273(259,282)$ & $275(263,280)$ & 0.93 \\
\hline Epidural & & & & 0.27 & & & 1.00 \\
\hline No & $24(39 \%)$ & $19(43 \%)$ & $5(28 \%)$ & & $1(25 \%)$ & $23(40 \%)$ & \\
\hline Yes & $37(60 \%)$ & $24(55 \%)$ & $13(72 \%)$ & & $2(50 \%)$ & $35(60 \%)$ & \\
\hline
\end{tabular}

$B M I$ body mass index, $l q$ lower quartile, $u q$ upper quartile, $P V R$ post-void residual

Table 3 Hazard ratios (HR) for demographic and obstetric parameters. No factor significantly influenced time to normalization of residual urine volume

\begin{tabular}{lll}
\hline & HR $(95 \% \mathrm{CI})$ & $p$ value \\
\hline Age (years) & $1.00(0.97-1.03)$ & 0.864 \\
Parity & $1.00(0.85-1.16)$ & 0.969 \\
Parity $>1$ & $0.93(0.56-1.56)$ & 0.780 \\
BMI $\left(\mathrm{kg} / \mathrm{m}^{2}\right)$ & $1.00(0.94-1.07)$ & 0.931 \\
Spontaneous delivery & $1.04(0.50-2.16)$ & 0.915 \\
1st stage of labor (per $10 \mathrm{~min})$ & $1.00(0.99-1.02)$ & 0.968 \\
2nd stage of labor (per $10 \mathrm{~min})$ & $1.00(0.96-1.04)$ & 0.830 \\
Head circumference $($ per $5 \mathrm{~cm})$ & $0.93(0.44-1.94)$ & 0.839 \\
Epidural analgesia & $1.11(0.66-1.86)$ & 0.688 \\
\hline
\end{tabular}

$B M I$ body mass index, $C I$ confidence interval

large number of ties (multiple events occurring at the same time point), Cox regression is unlikely to be very accurate.

The idea of PUR being transient and self-limiting [1] has to be questioned. This belief might explain why postpartum urinary retention management guidelines are not yet established [1] but urgently needed in clinical practice [48]. Data on PUR management are insufficient, particularly because treatment options differ widely between studies. Protocols of timed voiding and routine measurement of PVR have been shown to reduce PUR [10, 13, 56]. Even if routine screening is not yet recommended [1], adequate symptom assessment by the health care provider after delivery is of utmost importance [23, 48, 57]. Last but not least, knowledge of PUR is considered to be low amongst residents in obstetrics and gynecology and management guidelines increase their comfort in dealing with patients in the postpartum period [58].

The strength of the current study is the rather large number of patients who have meticulously been followed up for 36 months; a weakness might be that we did not perform repetitive multichannel urodynamics to indicate when detrusor contractility did resume. However, with urodynamics being an invasive and expensive technique that has little value for therapeutical options in urinary retention we considered additional urodynamics as not really helpful. A further weakness is that the results reflect our single-center experience only.

In summary, long-term follow-up data show that acute PUR may have long-term consequences for the patients' voiding abilities [1]. It is not known if normalization of the PVR implies that the patient does not develop symptoms or complications in later life [1]. The longer acute retention lasts without treatment, the more likely it is that the detrusor muscle is transformed into noncontractile fibrosis [59], 
which explains acontractility in our patients and potentially in later life. Misdiagnosis or delay in diagnosis of PUR can cause bladder overdistension, leading to irreversible detrusor damage. This argues for careful monitoring and early diagnosis of PUR to prevent immediate and long-term sequelae [6], particularly amongst women who underwent operative vaginal deliveries according to the high rate of operative vaginal deliveries in our cohort.

Future research needs to compare expectant and active management of PUR before stating that covert PUR does not need treatment [1]. Management strategies, adverse effects of PUR, catheterization methods, whether catheterization prevents morbidity, and the necessity for screening and treating PUR need to be studied $[1,10]$. Until then, unifying clinical practice and increasing obstetric awareness of this common condition is indicated $[1,56]$, because, according to our results, long-term morbidity of PUR is rare but has devastating consequences for the few women suffering from voiding difficulties.

Contributions S. Mohr: data management, data analysis, manuscript writing, approval of the final manuscript; L. Raio: data collection, data analysis, approval of the final manuscript; U. Gobrecht-Keller: data collection, data management, approval of the final manuscript; S. Imboden: data collection, data analysis, approval of the final manuscript; M.D. Mueller: manuscript editing, approval of the final manuscript; A. Kuhn: project development, data collection, manuscript editing, approval of the final manuscript.

Funding Open access funding provided by University of Bern.

\section{Declarations}

\section{Conflicts of interest None.}

Financial None (all authors)

Open Access This article is licensed under a Creative Commons Attribution 4.0 International License, which permits use, sharing, adaptation, distribution and reproduction in any medium or format, as long as you give appropriate credit to the original author(s) and the source, provide a link to the Creative Commons licence, and indicate if changes were made. The images or other third party material in this article are included in the article's Creative Commons licence, unless indicated otherwise in a credit line to the material. If material is not included in the article's Creative Commons licence and your intended use is not permitted by statutory regulation or exceeds the permitted use, you will need to obtain permission directly from the copyright holder. To view a copy of this licence, visit http://creativecommons.org/licenses/by/4.0/.

\section{References}

1. Mulder FEM, Hakvoort RA, Schoffelmeer MA, et al. Postpartum urinary retention: a systematic review of adverse effects and management. Int Urogynecol J Pelvic Floor Dysfunct. 2014;25:1605-12. https://doi.org/10.1007/s00192-014-2418-6.

2. Groutz A, Levin I, Gold R, et al. Protracted postpartum urinary retention: the importance of early diagnosis and timely intervention. Neurourol Urodyn. 2011;30:83-6. https://doi.org/10.1002/ nau.20926.

3. Avondstondt AM, Hidalgo RJ, Salamon CG. Intrapartum risk factors for postpartum urinary retention: a case-control study. Int Urogynecol J. 2020;31:2395-8. https://doi.org/10.1007/ s00192-020-04378-2.

4. Yip SK, Brieger G, Hin LY, Chung T. Urinary retention in the post-partum period. The relationship between obstetric factors and the post-partum post-void residual bladder volume. Acta Obstet Gynecol Scand. 1997;76:667-72. https://doi.org/10.3109/00016 349709024608.

5. Choe WS, Kwang Ng B, Atan IK, Lim PS. Acceptable postvoid residual urine volume after vaginal delivery and its association with various obstetric parameters. Obstet Gynecol Int. 2018;2018:5971795. https://doi.org/10.1155/2018/5971795.

6. Ain QU, Shetty N, Suprika K. Postpartum urinary retention and its associated obstetric risk factors among women undergoing vaginal delivery in tertiary care hospital. J Gynecol Obstet Hum Reprod. 2021;50:101837. https://doi.org/10.1016/j.jogoh.2020.101837.

7. Teo R, Punter J, Abrams K, et al. Clinically overt postpartum urinary retention after vaginal delivery: a retrospective case-control study. Int Urogynecol J. 2007;18:521-4. https://doi.org/10.1007/ s00192-006-0183-x.

8. Kekre AN, Vijayanand S, Dasgupta R, Kekre N. Postpartum urinary retention after vaginal delivery. Int J Gynecol Obstet. 2011;112:112-5. https://doi.org/10.1016/j.ijgo.2010.08.014.

9. Carley ME, Carley JM, Vasdev G, et al. Factors that are associated with clinically overt postpartum urinary retention after vaginal delivery. Am J Obstet Gynecol. 2002;187:430-3. https://doi.org/ 10.1067/mob.2002.123609.

10. Glavind K, Bjørk J. Incidence and treatment of urinary retention postpartum. Int Urogynecol J. 2003;14:119-21. https://doi.org/ 10.1007/s00192-002-1014-3.

11. Suzuki S, Kakizaki E, Kobayashi R, Teshima S. Risk factors for postpartum urinary retention after vaginal delivery at term without epidural anesthesia. J Matern Neonatal Med. 2019;32:3470-2. https://doi.org/10.1080/14767058.2018.1465559.

12. Chai AHL, Wong T, Mak HLJ, et al. Prevalence and associated risk factors of retention of urine after caesarean section. Int Urogynecol J. 2008;19:537-42. https://doi.org/10.1007/ s00192-007-0470-1.

13. Buchanan J, Beckmann M. Postpartum voiding dysfunction: identifying the risk factors. Aust N Z J Obstet Gynaecol. 2014;54:415. https://doi.org/10.1111/ajo.12130.

14. Gupta A, Pampapati V, Khare C, et al. Postpartum urinary retention in women undergoing instrumental delivery: a cross-sectional analytical study. Acta Obstet Gynecol Scand. 2021;100:41-7. https://doi.org/10.1111/aogs.13954.

15. Demaria F, Boquet B, Porcher R, et al. Post-voiding residual volume in 154 primiparae 3 days after vaginal delivery under epidural anesthesia. Eur J Obstet Gynecol Reprod Biol. 2008;138:110-3. https://doi.org/10.1016/j.ejogrb.2007.12.003.

16. Mulder FEM, Rengerink KO, van der Post JAM, et al. Deliveryrelated risk factors for covert postpartum urinary retention after vaginal delivery. Int Urogynecol J. 2016;27:55-60. https://doi.org/ 10.1007/s00192-015-2768-8.

17. Gonzalez-Díaz E, Biurrun GP. Levator ani muscle avulsion: a risk factor for persistent postpartum voiding dysfunction. Int Urogynecol J. 2020;31:2327-35. https://doi.org/10.1007/ s00192-020-04412-3.

18. Cavkaytar S, Kokanalı MK, Baylas A, et al. Postpartum urinary retention after vaginal delivery: assessment of risk factors in a 
case-control study. J Turkish Ger Gynecol Assoc. 2014;15:140-3. https://doi.org/10.5152/jtgga.2014.13102.

19. Mevorach Zussman N, Gonen N, Kovo M, et al. Protracted postpartum urinary retention-a long-term problem or a transient condition? Int Urogynecol J. 2020;31:513-9. https://doi.org/10. 1007/s00192-019-03903-2.

20. Mulder FEM, Hakvoort RA, de Bruin JP, et al. Long-term micturition problems of asymptomatic postpartum urinary retention: a prospective case-control study. Int Urogynecol J. 2018;29:481-8. https://doi.org/10.1007/s00192-017-3457-6.

21. Clancy AA, Pascali D. Bladder distension injury secondary to postpartum urinary retention. J Obstet Gynaecol Can. 2019;41:1069-70. https://doi.org/10.1016/j.jogc.2018.05.001.

22. Dueñas-García OF, Rico H, Gorbea-Sanchez V, Herrerias-Canedo T. Bladder rupture caused by postpartum urinary retention. Obstet Gynecol. 2008;112:481-2. https://doi.org/10.1097/AOG.0b013 e31817997a4.

23. Mulder FEM, Schoffelmeer MA, Hakvoort RA, et al. Risk factors for postpartum urinary retention: a systematic review and meta-analysis. BJOG. 2012;119:1440-6. https://doi.org/10. 1111/j.1471-0528.2012.03459.x.

24. Lim JL. Post-partum voiding dysfunction and urinary retention. Aust N Z J Obstet Gynaecol. 2010;50:502-5. https://doi.org/10. 1111/j.1479-828X.2010.01237.x.

25. Barba M, Frigerio M, Manodoro S, et al. Postpartum urinary retention: absolute risk prediction model. Low Urin Tract Symptoms. 2021;13:257-63. https://doi.org/10.1111/luts.12362.

26. Humburg J, Troeger C, Holzgreve W, Hoesli I. Risk factors in prolonged postpartum urinary retention: an analysis of six cases. Arch Gynecol Obstet. 2011;283:179-83. https://doi.org/ 10.1007/s00404-009-1320-9.

27. Ching-Chung L, Shuenn-Dhy C, Ling-Hong T, et al. Postpartum urinary retention: assessment of contributing factors and longterm clinical impact. Aust N Z J Obstet Gynaecol. 2002;42:36770. https://doi.org/10.1111/j.0004-8666.2002.00367.x.

28. Stephansson O, Sandström A, Petersson G, et al. Prolonged second stage of labour, maternal infectious disease, urinary retention and other complications in the early postpartum period. BJOG. 2016;123:608-16. https://doi.org/10.1111/1471-0528. 13287.

29. Musselwhite KL, Faris P, Moore K, et al. Use of epidural anesthesia and the risk of acute postpartum urinary retention. Am J Obstet Gynecol. 2007;196:472.e1-5. https://doi.org/10.1016/j.ajog.2006. 11.031 .

30. Yip SK, Sahota D, Pang MW, Chang A. Screening test model using duration of labor for the detection of postpartum urinary retention. Neurourol Urodyn. 2005;24:248-53. https://doi.org/10. 1002/nau.20111.

31. Lamblin $\mathrm{G}$, Chene $\mathrm{G}$, Aeberli $\mathrm{C}$, et al. Identification of risk factors for postpartum urinary retention following vaginal deliveries: a retrospective case-control study. Eur J Obstet Gynecol Reprod Biol. 2019;243:7-11. https://doi.org/10.1016/j.ejogrb.2019.10. 001.

32. Perú Biurrun G, Gonzalez-Díaz E, Fernández Fernández C, Fernández Corona A. Post partum urinary retention and related risk factors. Urology. 2020;143:97-102. https://doi.org/10.1016/j. urology.2020.03.061.

33. Tiberon A, Carbonnel M, Vidart A, et al. Risk factors and management of persistent postpartum urinary retention. J Gynecol Obstet Hum Reprod. 2018;47:437-41. https://doi.org/10.1016/j.jogoh. 2018.08.002.

34. Rosenberg M, Many A, Shinar S. Risk factors for overt postpartum urinary retention - the effect of the number of catheterizations during labor. Int Urogynecol J. 2020;31:529-33. https://doi.org/ 10.1007/s00192-019-04010-y.
35. Hakenberg OW, Ryall RL, Langlois SL, Marshall VR. The estimation of bladder volume by sonocystography. J Urol. 1983;130:249_ 51. https://doi.org/10.1016/S0022-5347(17)51087-3.

36. Abrams P, Cardozo L, Fall M, et al. The standardisation of terminology of lower urinary tract function: report from the standardisation sub-committee of the international continence society. Neurourol Urodyn. 2002;21:167-78. https://doi.org/10.1002/nau. 10052 .

37. Huang AJ, Brown JS, Boyko EJ, et al. Clinical significance of postvoid residual volume in older ambulatory women. J Am Geriatr Soc. 2011;59:1452-8. https://doi.org/10.1111/j.1532-5415. 2011.03511.x.

38. Kaplan SA, Wein AJ, Staskin DR, et al. Urinary retention and post-void residual urine in men: separating truth from tradition. $\mathrm{J}$ Urol. 2008;180:47-54. https://doi.org/10.1016/j.juro.2008.03.027.

39. Asimakopoulos AD, De Nunzio C, Kocjancic E, et al. Measurement of post-void residual urine. Neurourol Urodyn. 2016;35:557. https://doi.org/10.1002/nau.22671.

40. Khayyami Y, Klarskov N, Lose G. Post-void residual urine under $150 \mathrm{ml}$ does not exclude voiding dysfunction in women. Int Urogynecol J. 2016;27:467-73. https://doi.org/10.1007/ s00192-015-2854-y.

41. Geller EJ. Prevention and management of postoperative urinary retention after urogynecologic surgery. Int J Womens Health. 2014;6:829. https://doi.org/10.2147/IJWH.S55383.

42. Negro CLA, Muir GH. Chronic urinary retention in men: how we define it, and how does it affect treatment outcome. BJU Int. 2012;110:1590-4. https://doi.org/10.1111/j.1464-410X.2012. 11101.x.

43. Fleming AR. The use of urecholine in the prevention of postpartum urinary retention; final report. Am J Obstet Gynecol. 1957;74:569-71. https://doi.org/10.1016/0002-9378(57)90509-4.

44. Mulder FEM, Hakvoort RA, de Bruin JP, et al. Comparison of clean intermittent and transurethral indwelling catheterization for the treatment of overt urinary retention after vaginal delivery: a multicentre randomized controlled clinical trial. Int Urogynecol J. 2018;29:1281-7. https://doi.org/10.1007/s00192-017-3452-y.

45. Niël-Weise BS, van den Broek PJ. Urinary catheter policies for short-term bladder drainage in adults. Cochrane Database Syst Rev. 2005;(3):CD00420. https://doi.org/10.1002/14651858. CD004203.pub2.

46. Neron M, Allègre L, Huberlant S, et al. Impact of systematic urinary catheterization protocol in delivery room on covert postpartum urinary retention: a before-after study. Sci Rep. 2017;7. https://doi.org/10.1038/s41598-017-18065-8.

47. Niël-Weise BS, van den Broek PJ, da Silva EM, Silva LA. Urinary catheter policies for long-term bladder drainage. Cochrane Database Syst Rev. 2012;(8):CD004201. https://doi.org/10.1002/ 14651858.CD004201.pub3.

48. Humburg J. Die postpartale Harnretention-klinisch bedeutungslos? Ther Umschau. 2008;65:681-5. https://doi.org/10.1024/ 0040-5930.65.11.681.

49. Zaki MM, Pandit M, Jackson S. National survey for intrapartum and postpartum bladder care: assessing the need for guidelines. BJOG. 2004;111:874-6. https://doi.org/10.1111/j.1471-0528. 2004.00200.x.

50. Salimans S, Govaerts J, de Jong N, et al. Three-dimensional bladder ultrasonography with the BladderScan ${ }^{\circledR}$ overestimates post void residual one week after delivery. Eur J Obstet Gynecol Reprod Biol. 2019;3:100030. https://doi.org/10.1016/j.eurox. 2019.100030.

51. Jensen JT, Klarskov N, Lauenborg J. Validity of bladder volume measurement by ultrasound in women postpartum. Int Urogynecol J. 2020;31:643-9. https://doi.org/10.1007/s00192-019-04037-1.

52. Mulder FEM, van der Velde S, Pol F, et al. Accuracy of postvoid residual volumes after vaginal delivery: a prospective equivalence 
study to compare an automatic scanning device with transurethral catheterization. Int Urogynecol J. 2019;30:773-8. https://doi.org/ 10.1007/s00192-018-3700-9.

53. Yip SK, Sahota D, Chang AMZ. Determining the reliability of ultrasound measurements and the validity of the formulae for ultrasound estimation of postvoid residual bladder volume in postpartum women. Neurourol Urodyn. 2003;22:255-60. https:// doi.org/10.1002/nau.10112.

54. Nusee Z, Ibrahim N, Rus RM, Ismail H. Is portable three-dimensional ultrasound a valid technique for measurement of postpartum urinary bladder volume? Taiwan J Obstet Gynecol. 2014;53:12-6. https://doi.org/10.1016/j.tjog.2013.01.028.

55. Lukasse M, Cederkvist HR, Rosseland LA. Reliability of an automatic ultrasound system for detecting postpartum urinary retention after vaginal birth. Acta Obstet Gynecol Scand. 2007;86:1251-5. https://doi.org/10.1080/00016340701621478.

56. Stanley AY, Conner BT. Implementing a clinical practice guideline to manage postpartum urinary retention. J Nurs Care Qual.
2015;30:175-80. https://doi.org/10.1097/NCQ.0000000000 000087 .

57. Leach S. "Have you had a wee yet?" postpartum urinary retention. Pract Midwife. 2011;14:23-5.

58. Napoe GS, Adjei NN, Cooper AC, et al. Postpartum urinary retention: a survey of obstetrics and gynaecology residents in the United States. J Obstet Gynaecol (Lahore). 2020;40:1118-21. https://doi.org/10.1080/01443615.2019.1706159.

59. Collado A, Batista E, Gelabert-Más A, et al. Detrusor quantitative morphometry in obstructed males and controls. J Urol. 2006;176:2722-8. https://doi.org/10.1016/j.juro.2006.07.131.

Publisher's note Springer Nature remains neutral with regard to jurisdictional claims in published maps and institutional affiliations. 